\title{
Improvement of Surface Wettability and Hydrophilization of Poly-paraphenylene benzobisoxazole Fiber with Fibrillation Combined Oxygen Plasma Treatment
}

\author{
XIWEN WANG, JIAN HU, AND YUN LIANG \\ State Key Lab of Pulp and Paper Engineering, South China University of Technology, \\ Wushan road No.381, Guangzhou, China. \\ wangxw@scut.edu.cn
}

Received 09 September 2011; Accepted 11 November 2011

\begin{abstract}
A new surface modification method fibrillation combined with oxygen plasma treatment to improve the wettability and hydrophily of PBO fiber was studied in this paper. The surface chemical structure and morphology of PBO fiber were characterized by the methods of FTIR, XPS and SEM. The wettability and hydrophlic characters changes on the surface were evaluated by the dynamic contact angle system and image analysis. The results show that the increase surface roughness by fibrillation could improve the wettability. Fibrillation combined oxygen plasma treatment has a better effect than oxygen plasma treatment to improve the wettability and hdyrophlization of PBO fiber. The specific area of PBO fiber increased to $10.7 \mathrm{~m}^{2} / \mathrm{g}$ from $0.7 \mathrm{~m}^{2} / \mathrm{g}$, contact angle decreased to $43.2^{\circ}$ from $84.4^{\circ}$ and WRV increased to $208.4 \%$ from $13.7 \%$. The modified fibers have a good dispersion in water for hydrophilization improvement.
\end{abstract}

Keywords: PBO fiber; Surface treatment; Plasma.

\section{Introduction}

Poly-paraphenylene benzobisoxazole (PBO) fiber is one of aromatic heterocyclic ring polymeric fibers which exhibits excellent mechanical properties companied by equally impressive thermal properties 1-8. Due to its excellent thermal stability, excellent strength and high wear resistance. PBO fiber provides great potential applications in functional composite materials. PBO fiber can be also used for papermaking engineering, friction materials and sealing materials. Because of the chemically inert surface of the fiber, several surface modification methods were proposed for PBO fibers, including chemical treatment, plasma treatment, electrolytic oxidation, and coupling agents 9-13. In these modification methods, plasma treatment, especially oxygen plasma treatment shows a better effect 14 . Because of poor wettability and hydrophlic characters, PBO fiber could not disperse homogeneous in water. It restricts PBO fibers applying in papermaking engineering, friction materials and other fields. However, the improvement of surface wettability and hydrophily 
properties of $\mathrm{PBO}$ fibers has been rarely reported in the literature. In this paper, we present a new treatment FCOP (fibrillation combined oxygen plasma) to improve the wettability and hydrophlic properties.

\section{Material and methods}

\section{Materials}

PBO fiber: Zylon AS type, purchased from Toyobo Ltd. Co., Japan. The fibers were cleaned with ethanol and distilled water respectively and then dried in a vacuum oven at $100^{\circ} \mathrm{C}$ for $12 \mathrm{~h}$.

\section{Fibrillation of the fibers}

The dried fibers were treated with different consistence $\mathrm{KMnO}_{4} / \mathrm{H}_{2} \mathrm{SO}_{4}$ for 3 minute. Then washed fibers with distilled water and dried in a vacuum oven at $100^{\circ} \mathrm{C}$ for $12 \mathrm{~h}$. The pretreated fibers were fibrillated by vibrating ball mil with different treatment time 15 .

\section{Oxygen plasma treatment}

The original PBO fibers and fibrillated fibers were treated by plasma in the atmosphere of Oxygen. The oxygen plasma treatment was operated at chamber pressure $1.50 \pm 0.05$ mbar for $3 \mathrm{~min}$, which the plasma resonance frequency was $30 \mathrm{MHz}$, the reactor power was $30 \mathrm{~W}$, and the gas flow was $4.5 \mathrm{~mL} / \mathrm{min}$. The treating temperature was under $25^{\circ} \mathrm{C}$.

\section{Fiber Characteization}

\section{Chemical Strructure and Surface elemental Composition Analysis}

The surface chemical structure was analyzed by the method of Fourier transform infrared spectroscope (FTIR) and the surface elemental composition analysis was detested by the method of X-ray photoelectron spectroscopy (XPS).

\section{Surface morphology of the fibers}

The changes of the PBO fiber after etching were observed by light microscope and scanning electron microscope. The thin conducting layer of gold were vacuum-sputtered onto the surface of the treated fibers, and the samples were observed with scanning electron microscope (SEM, LEO 1530VP, Germany).

\section{Wettability of the fibers}

The contact angles between fiber and water were measured by the dynamic contact angle analysis system (Data physics, OCA20, Germany).

Water retention values of PBO fibers were studied to evaluate wettability of fibers. The experiment was carried out according to the ASTM D-570 method.

$$
\text { WRV }(\%)=M w-M c / M c \times 100 \%
$$

where $M w$ and $M c$ stand for the wet weight and the conditioned weight of fiber specimens, respectively.

\section{Specific surface}

Specific surface area estimates were obtained using Nitrogen as gas adsorbent and the BET model with Nova-1000.

\section{Dispersion character}

The dispersion character of PBO fibers in water was characterized by image analysis. Put $10 \mathrm{~g}$ fibers to the $1000 \mathrm{~g}$ water in a beaker, agitation for $1 \mathrm{~min}$. Then record the dispersion status by digital camera to analyze the fiber dispersion character after 20 seconds. 


\section{Results and discussion}

\section{Pretreatment of $P B O$ fiber}

PBO fiber is a typical skin-core model fiber. The core of the fiber is made of elementary fiber with high oriented and crystallized microfibrils. Etching solution-- $\mathrm{KMnO}_{4} / \mathrm{H}_{2} \mathrm{SO}_{4}$ was used to damage the shin of the PBO fiber surface. The morphology of PBO fibers etched by the solutions with different consistency for $3 \mathrm{~min}$ was shown in Fig.1.

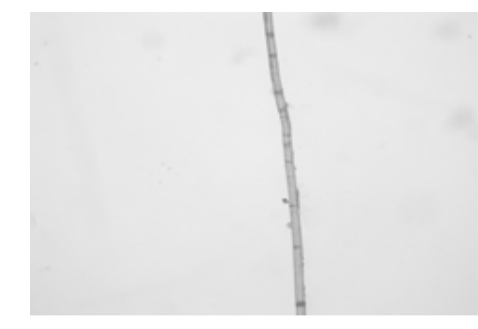

$\mathrm{A} 0.2 \mathrm{~g} / \mathrm{L}$

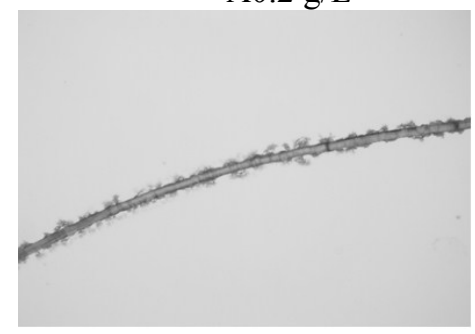

$\mathrm{C} 1.0 \mathrm{~g} / \mathrm{L}$

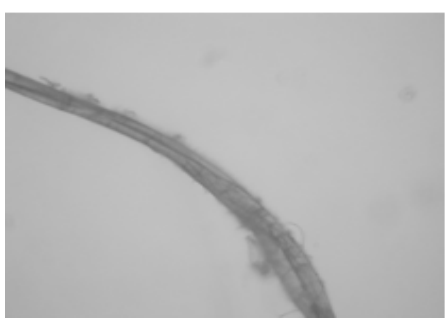

B $0.5 \mathrm{~g} / \mathrm{L}$

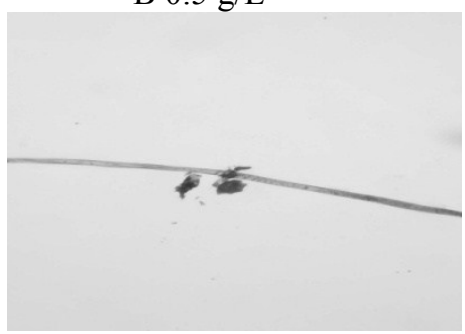

$\mathrm{D} 1.5 \mathrm{~g} / \mathrm{L}$

Figure 1. Morphology of $\mathrm{PBO}$ fibers after echting.

From Fig. 1, it can be seen that the surface of PBO fiber was smooth after the $0.2 \mathrm{~g} / \mathrm{L}$ etching solution treatment. When the etching solution consistency increased to $0.5 \mathrm{~g} / \mathrm{L}$, cracks appeared on the fiber surface and the mircrofibrils exposed on the surface of the fiber. At the same time the fiber diameter was increased as fiber swelled. When the consistency got to $1.0 \mathrm{~g} / \mathrm{L}$, the void-free region was break off and more mircrofibrils were exposed (as seen in Fig.2). The surface roughness was greatly increased. However, the fiber was serious destroyed at the $1.5 \mathrm{~g} / \mathrm{L}$ consistency of etching solution. At this time microfibrils were disappeared again and the fiber diameter became thin. So the optional pretreatment consistency for etching was $1.0 \mathrm{~g} / \mathrm{L}$.
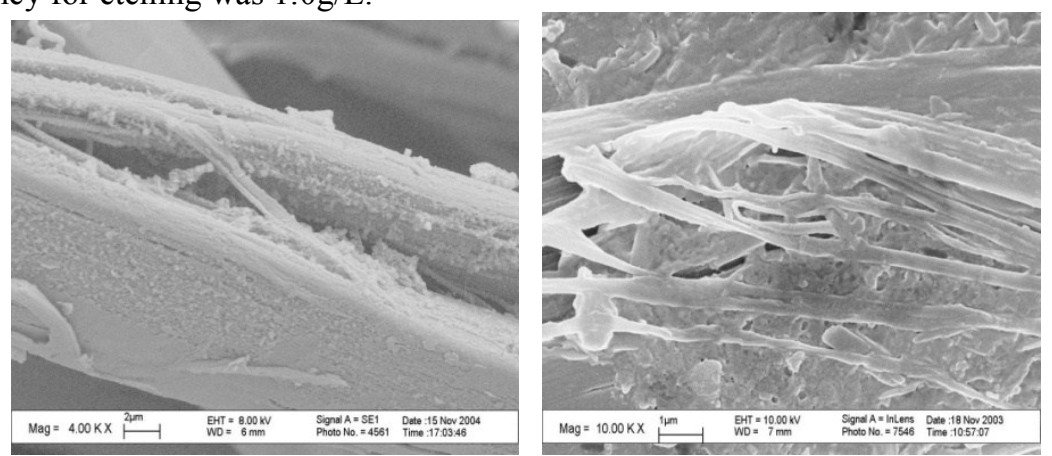

Figure 2. Microfibrisl on PBO fiber surface. 


\section{Fibrillation}

The pretreated fibers were fibrillated with vibrating ball mill. Properties of the fibrillated fiber at different time were listed in Table 1.

Table 1. Properties of the fibrillated fiber.

\begin{tabular}{llll}
\hline $\begin{array}{l}\text { Treat time } \\
(\min )\end{array}$ & $\begin{array}{l}\text { Specific surface } \\
\text { area }\left(\mathrm{m}^{2} / \mathrm{g}\right)\end{array}$ & Contact angle with water & WRV $(\%)$ \\
\hline original fiber & 0.7 & $84.4^{\circ}$ & 13.7 \\
5 & 3.2 & $74.2^{\circ}$ & 40.2 \\
10 & 6.7 & $65.8^{\circ}$ & 100.1 \\
15 & 8.9 & $60.2^{\circ}$ & 142.5 \\
20 & 9.7 & $55.4^{\circ}$ & 178.4 \\
\hline
\end{tabular}

It can be seen from the Table. 1 that the properties of the fibrillated fibers at different treatment time had great distinction. The sepecail surface area, contact angle and WRV were increased with treatment time increase. When treatment time at $20 \mathrm{~min}$, the specific surface area was $9.7 \mathrm{~m}^{2} / \mathrm{g}$, and which was more than 13 times of the original fiber. The surface roughness was increased greatly. The contact angle decreased from $84.4^{\circ}$ to $55.4^{\circ}$ and the WRV increased from $13.7 \%$ to $178.4 \%$. It indicated that the surface roughness increase could improve the wettability of the PBO fibers. The morphology (SEM) of fibrillated fiber at 20 min treatment time were shown in Fig.3. The mricrofibrls and branched fibers were clearly seen on the surface of the fiber with fibrillation treatment. The FTIR spectrum of fibrillated fiber and original fiber were shown in Fig.4.

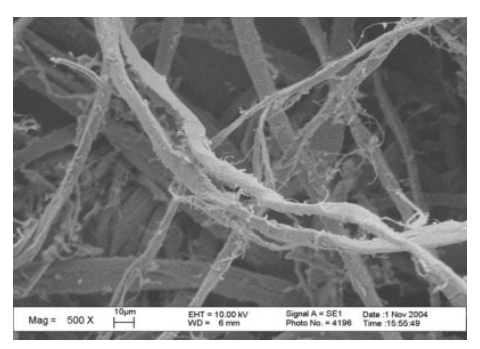

$\times 500$

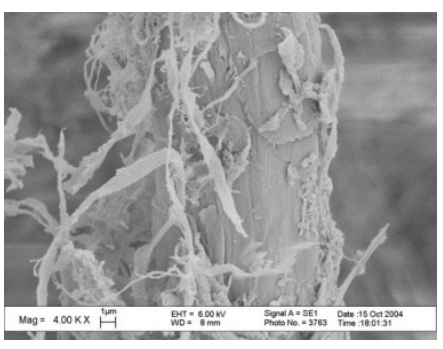

$\times 4000$

Figure 3. Morphology of fibrillated fibers.

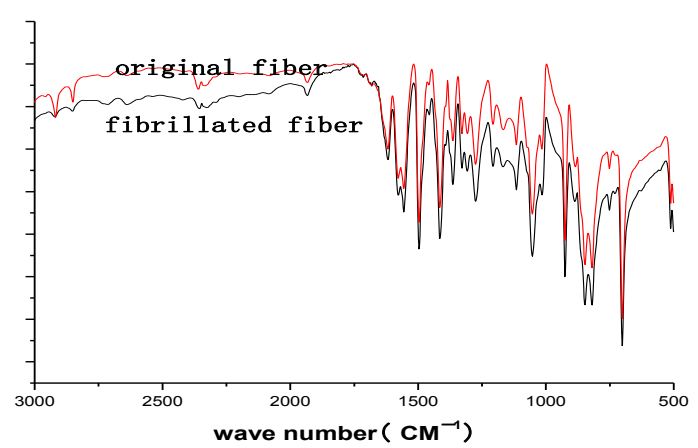

Figure 4. FTIR of origin and fibrillated fibers. 
From the Fig.4, it was shown that the two FTIR curves were almost the same, and which could be deduced that the fibrillation only destroyed the amorphous region of the fiber and not change the chemical structure of the fiber.

\section{Fibrillation combined oxygen plasma treatment}

Table 2. The surface elemental composition results by XPS.

\begin{tabular}{llll}
\hline $\begin{array}{l}\text { Atomic } \\
\text { percent }\end{array}$ & $\begin{array}{l}\text { Fibrillated } \\
\text { fiber }\end{array}$ & $\begin{array}{l}\text { oxygen plasma } \\
\text { treated }\end{array}$ & $\begin{array}{l}\text { FCOP } \\
\text { treated }\end{array}$ \\
\hline $\mathrm{C}$ & $74.9 \%$ & $73.1 \%$ & $62.5 \%$ \\
$\mathrm{O}$ & $15.3 \%$ & $22.6 \%$ & 27.2 \\
$\mathrm{~N}$ & $9.9 \%$ & $4.3 \%$ & $10.4 \%$ \\
$\mathrm{O} / \mathrm{C}$ & $20 \%$ & $31 \%$ & $44 \%$ \\
\hline
\end{tabular}

The results of XPS analysis of PBO fibers after FCOP treatment were shown in Table 2. From Table 2, it can be seen that the oxygen composition on the surface of the fiber increased to $22.6 \%$ from $15.3 \%$ (original fiber) after oxygen plasma treatment and the oxygen-to-carbon $(\mathrm{O} / \mathrm{C})$ ratio also increased to $31 \%$ from $20 \%$. Compared with the fiber of oxygen plasma treated fiber and FCOP treated fiber, the oxygen elemental of the later was almost 5 percent higher than the former and the $\mathrm{O} / \mathrm{C}$ ratio was also increased 13 percent. The fibrillated fiber had a lot of mircofibrils, branched fibers and big specific surface area. So it increased the chance to react with the oxygen plasma during the treatment. The XPS results indicated that the oxygen plasma treatment process introduced polar groups to the fiber surface.

The properties of treated fiber were shown in Table 3. The specific surface area of FCOP treated fiber was much higher than that of the PBO fiber. The contact angle with water of the FCOP treated fiber decreased to $43.2^{\circ}$ from $84.4^{\circ}$ (original fiber). And the WRV increased to $204.8 \%$. It showed that the wettability of the fiber improved.

Table 3. Wettability and hydrophilic properties of modified fibers.

\begin{tabular}{lllc}
\hline Fiber type & $\begin{array}{l}\text { Specific surface } \\
\text { area }\left(\mathrm{m}^{2} / \mathrm{g}\right)\end{array}$ & $\begin{array}{l}\text { WRV } \\
(\%)\end{array}$ & $\begin{array}{c}\text { Contact angle with } \\
\text { water }\end{array}$ \\
\hline Fibrillated & 9.7 & 178.4 & $54.4^{\circ}$ \\
Oxygen treated & 1.0 & 60.2 & $49.3^{\circ}$ \\
FCOP treated & 10.8 & 204.8 & $43.2^{\circ}$ \\
\hline
\end{tabular}

The improvement of wettability also proved that the polar groups were increased to the PBO surface by the oxygen plasma treatment from the results. This was in accordance with the results of XPS analysis. Compared the fibrillated fiber, oxygen plasma treated fiber and the combined treated fiber, the combined treated fiber had a bigger WRV and a lower contact angle with water. It showed that fibrillation combined oxygen plasma treatment had much better modified effect than the oxygen plasma treatment. Because of bigger surface area on the fibrillated fiber surface, the reaction chance with oxygen plasma was greatly increased than untreated fiber. So the synergetic treated was effective method to improve the surface property of PBO fibers.

\section{Dispersion character}

The dispersion image of PBO fibers in water with different treatment were shown in Fig.5. 

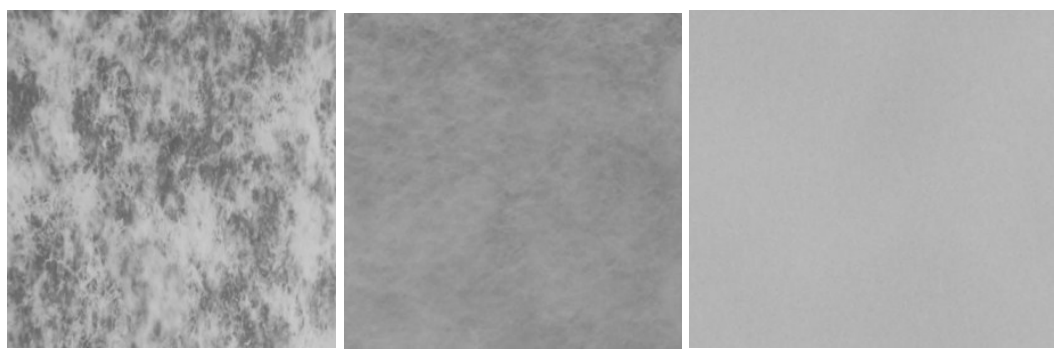

A. Fibrillated fiber B. Oxygen plasma treated fiber C. FCOP treated fiber

Figure 5. Dispersion image of PBO fibers.

It was shown in Fig.5 that the dispersion of the fibrillated fiber (Fig.5-A) was very bad and the fiber flocculated fastly. The dispersion of the oxygen plasma treated fiber (Fig.5-B) was much better than that of fibrillated fiber in uniformity. But the fiber flocculation was also found in this system. The dispersion image of FCOP treated fiber (Fig.5-C) had a good uniformity and stability. The improvement of dispersion characters in water was caused by the increase of hydrophilic properties of PBO fiber after FCOP treatment.

\section{Conclusions}

The pretreatment of treatment of $\mathrm{KMnO}_{4} / \mathrm{H}_{2} \mathrm{SO}_{4}$ solution and fibrillation can increase the roughness rather than introduce active functional groups on the surface of PBO fiber. Surface roughness increase could improve the wettability of the PBO fiber. Fibrillation combined oxygen plasma treatment was an effective method to modify the surface of PBO fiber. The specific area increased to $10.7 \mathrm{~m}^{2} / \mathrm{g}$ from $0.7 \mathrm{~m}^{2} / \mathrm{g}$, contact angle decreased to $43.2^{\circ}$ from $84.4^{\circ}$, WRV increased to $208.4 \%$ from $13.7 \%$. The FCOP treated fiber had a good uniformity and stability in water.

\section{References}

1. Bourbigot S; Flambard X.; Duquesne S. T. Poly. Int. 2001,50(1):157-164.

2. Chae HG; Kumar S. J Appl Polym. Sci. 2006,100(1):791-802.

3. Mader E; Melcher S.; Liu J.W.; Gao S.L. J. Mater. Sci. 2007,42(19):8047-52.

4. Wu G.M; Shyng Y.T. Composites A. 2004;35(11):1291-300.

5. Wu G.M; Hung C.H.; You J.H.; Liu S,J. J. Polym. Res. 2004,11(1):31-6.

6. Davies R.J.; Montes-Moran M.A.; Riekel C.; Young R.J. J. Mater. Sci. 2001,36(13):3079-3087.

7. Park J.M.; Kim D.S.; Kim S.R. J. Colloid. Interf. Sci. 2003,264(2):431-435.

8. Zhang C.H.; Huang Y.D.; Zhao Y.D. Mater. Chem Phys. 2005,92(1):245-250.

9. Park S.J. Seo M.K.; Lee J.R. J. Colloid. Interf. Sci. 2003,268(1):127-132.

10. Wu G.M.; Chang C.H. Vacuum. 2007,81(10):1159-1163.

11. Pan X.L.; Zhang R.Y.; Peng S.J. et al. Fiber and Polymers. 2010,11(3):372-373.

12. Zhang T.; Hu D.Y.; Jin J.H.; et al. Appl. Surf. Sci. 2010,256(7): 2073-2075

13. Zhang C.S.; Chen P.; Sun B.L.; et al. J. Appl. Polym. Sci. 2009,113(1):71-77

14. Wu G.M. Macro. Chem. Phys. 2004,85(1):81-87.

15. Hashimoto A.; Satoh M.; Iwasaki T.; Morita M. J.Mater.Sci. 2002, 37(18): 4013-4017 


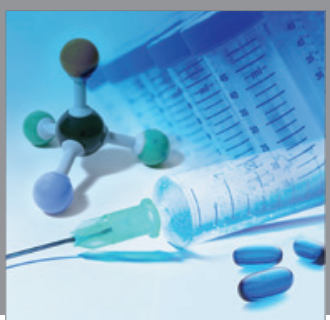

International Journal of

Medicinal Chemistry

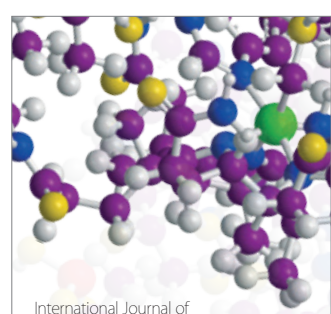

Carbohydrate Chemistry

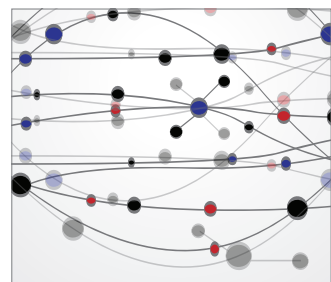

The Scientific World Journal
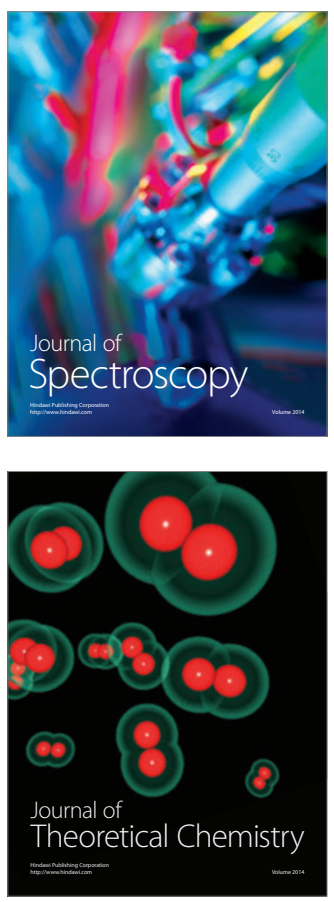
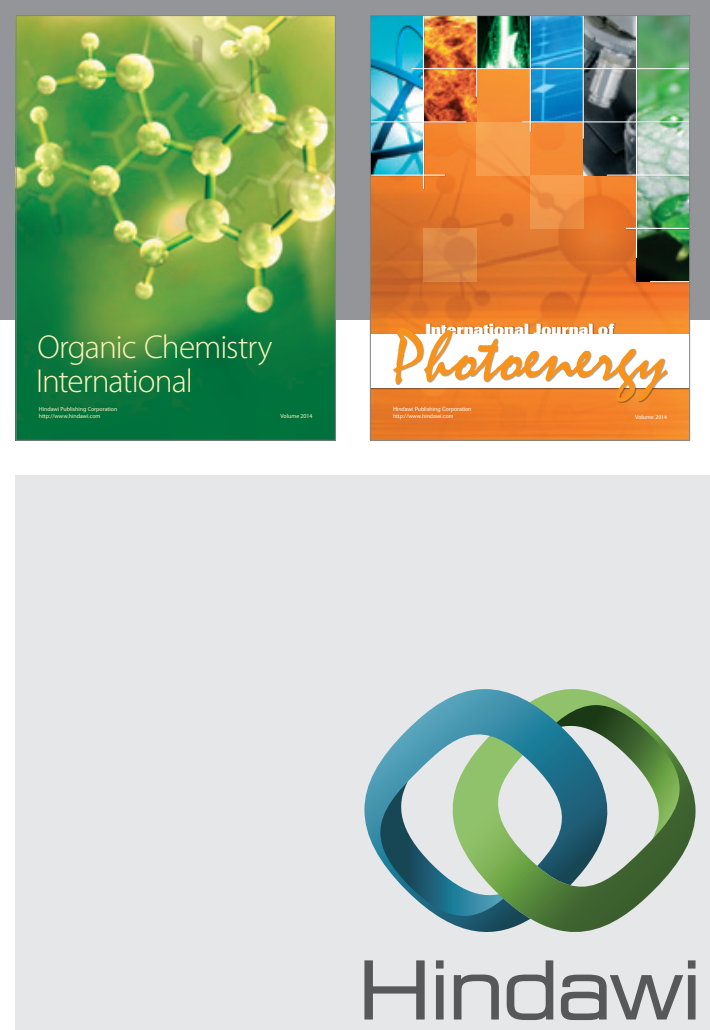

Submit your manuscripts at

http://www.hindawi.com
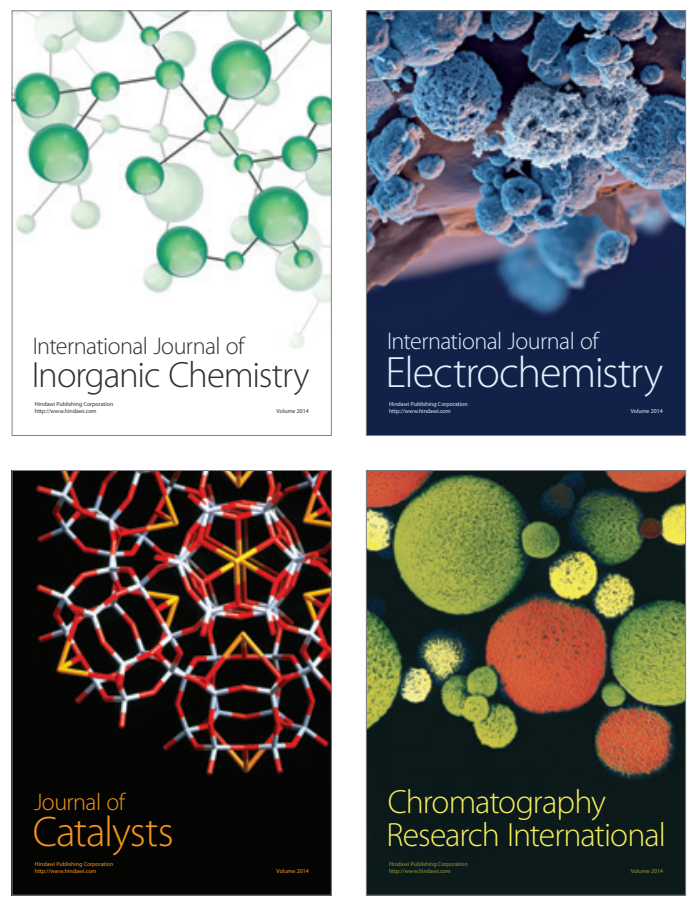
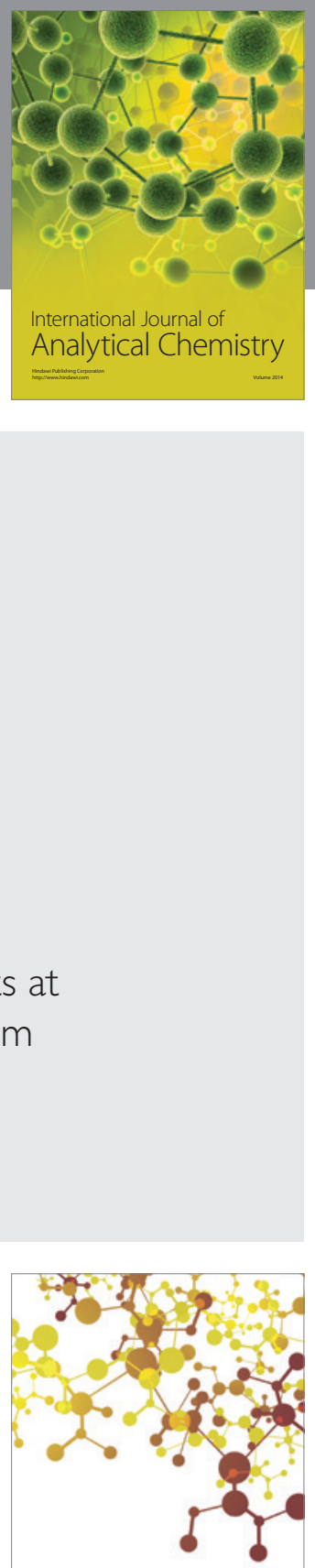

Journal of

Applied Chemistry
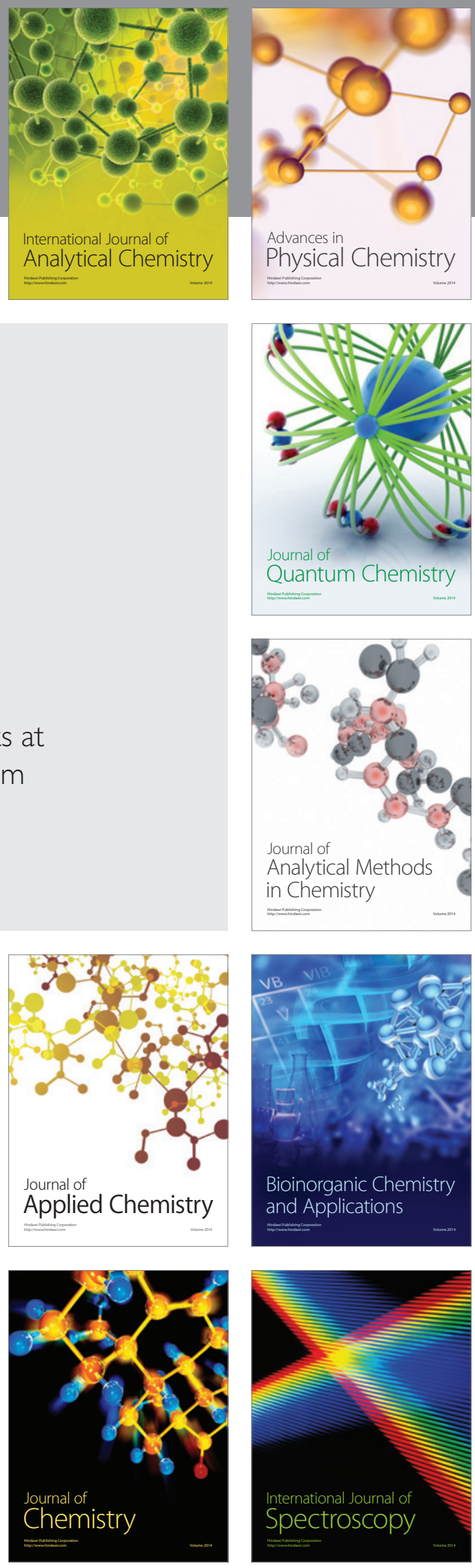